\title{
Reinado de Dios y revelación divina Ley y reinado de Dios
}

\section{Juan Barreto, Universidad de La Laguna, Tenerife, Centro de Reflexión Teológica, San Salvador.}

\section{Reinado de Dios y misión de Jesús}

Un concepto clave en el Nuevo Testamento es el de Reinado de Dios. El término griego basileia responde al arameo y hebreo malkût (reino, reinado, soberanía). Referido a Dios tiene siempre un sentido dinámico, se refiere al ejercicio de la actividad divina por la que reina sobre el hombre y el mundo: se trata del reinado de Dios ${ }^{1}$.

En los dos siglos anteriores al cristianismo, el concepto de realeza y reinado de Dios arraiga en las esperanzas del pueblo sobre todo por obra de la apocalíptica $^{2}$. Designaba el ejercicio de la soberanía divina en el eón presente (Dan 4,31 ) y la irrupción nueva y definitiva del reinado de Dios en el eón futuro (Dan 2, 44) . $^{3}$

Jesús adopta esa categoría del reinado de Dios pero de forma nueva. De hecho se puede decir que la expresión reinado de Dios (basileia tô̂ theô̂) es característica de Jesús. No aparece frecuentemente en la literatura del judaísmo

1. Cfr. J. Jeremias, Teología del Nuevo Testamento, I, Salamanca, 1974, pp. 121-126.

2. Ésta explicita y elabora proyectándolo hacia el futuro el concepto que constituye la esencia misma de la alianza: "Yo seré tu Dios/tú serás mi pueblo"; cfr. J. Bonsirven, Le Règne de Dieu, Toulouse, 1957, pp. 11-18. J. Gray, The biblical doctrine of the Reign of God, Edinburgh, 1999, piensa que este tema, central para la comprensión del Antiguo Testamento y del Nuevo Testamento, fue tratado por los profetas pre y postexílicos y atraviesa la apocalíptica. En los Salmos que se refieren a la realeza de Yavé se encontrarían los testimonios de su celebración ritual.

3. J. Jeremias, óp. cit., p. 120. 
antiguo. En Jesús es un concepto clave y la fraseología con la que se refiere a él no encuentra paralelo, en gran parte, en la literatura contemporánea ${ }^{4}$.

Marcos resume así el comienzo de la actividad pública de Jesús y el sentido de su misión: "El tiempo se ha cumplido, está cerca el reinado de Dios. Enmiéndense y crean en la buena noticia" (Mc 1, 15; cfr. Mt 4, 23; Lc 4, 43).

\section{Soberanía de Dios en el judaísmo contemporáneo}

La última era de la humanidad está caracterizada por esa irrupción divina a la que el hombre ha de responder y que excluye cualquier otro señorío. Ya la antigua profesión de fe del Deuteronomio proclamaba la exclusividad del Dios de Israel: "Escucha, Israel: Yavé es nuestro Dios, sólo Yavé" (Dt 6, 4). Esta confesión encabezaba la oración llamada Šema que todo israelita recitaba cada día. La primera parte contenía la confesión de fe en el Dios del cielo y de la tierra, expresando la total consagración del hombre a Él. La declaración de fe de esta parte se llamaba "tomar sobre sí el yugo de la soberanía celestial"'. En la oración llamada Qaddiš del culto sinagogal y del templo se pedía: "Que Él haga llegar su reinado y que germine su redención... ahora y en un futuro próximo"6.

Por reinado de Dios se entiende el ejercicio de su soberanía sobre el hombre. Pero ¿cómo entendían los contemporáneos de Jesús ese ejercicio de la soberanía divina? ¿En qué relación se sitúa con respecto al hombre? ¿Cuál es la resultante en el hombre de esta relación?

La esperanza judía de salvación ${ }^{7}$ tiene sin duda múltiples aspectos, pero se podría esquematizar en dos formas fundamentales: por una parte, la esperanza nacional, mesiánica; por otra, la esperanza cósmica, escatológica. Independientes en su origen, ambas corrientes se fueron encontrando poco a poco sin llegar a unificarse totalmente ${ }^{8}$.

La opinión dominante era que Dios enviaría al Rey-Mesías, al hijo de David, y restablecería por su medio el reino de Israel en el antiguo esplendor de las tribus reunidas, liberadas de la dominación extranjera y de la miseria, pero

4. Ibíd., pp. 46-50.

5. Cfr. J. Bonsirven, óp. cit., p. 25.

6. Cfr. íd., Textes Rabbiniques des deux premiers siècles chrétiens pour servir à l'intelligence du Nouveau Testament, Roma, 1955, p. 3. Para otros textos litúrgicos relacionados con el Reino cfr. íd., Le Régne de Dieu, óp. cit., pp. 22-25.

7. Para las expectativas de los judíos en tiempos de Jesús $c f r$. P. Grelot, L'espérance juive à l'heure de Jésus, París, 1978; y para los distintos niveles de esta esperanza de salvación cfr. J. L. Sicre, El cuadrante, II. La apuesta. El mundo de Jesús, Estella, 1997, pp. 300-304.

8. R. Schnackenburg, Reino y reinado de Dios, Madrid, 1974, pp. 51-52. 
también purificadas para asegurar el desarrollo fiel del culto y el exacto cumplimiento de la Ley ${ }^{9}$.

La instauración de este reinado presupone el castigo de los enemigos —así se entiende la liberación - y la imposición de la Ley. Estas condiciones vienen asumidas con distintos matices según las distintas corrientes de pensamiento que fácilmente se imbrican. En los medios zelotas y en ciertos documentos de Qumrán (cfr. el Rollo de la Guerra y la concepción de la lucha entre los hijos de la tiniebla y los hijos de la luz) parece predominar un ideal nacionalista que contempla la perspectiva de una acción violenta por el reinado de Dios y el reino teocrático de Israel ${ }^{10}$. En cambio, en los círculos fariseos el acento recae sobre el dominio expresado por el imperio de la Torá. La religión de la Ley les ha servido para profundizar en la realeza de Dios. Israel, que ha recibido el privilegio de la Ley, tiene que hacer reconocer a todos los pueblos el derecho del Señor por la profesión de un monoteísmo fiel y por el celo escrupuloso en la observancia legal ${ }^{11}$.

¿Qué postura adopta Jesús? Será oportuno comenzar examinando brevemente la postura de Jesús respecto a la Ley, tan recurrente en los evangelios. Es claro que Jesús entra en polémica a este respecto con las corrientes dominantes y que su divergencia no se refiere a la aplicación de este o aquel precepto, sino a la concepción global de la Ley. Esta distinta concepción tiene su raíz, como veremos, en la distinta comprensión de Dios y, por consiguiente, de la relación Dios/hombre, de la que Jesús se hace expresión y portavoz.

\section{Ley y soberanía divina}

\subsection{Palabra normativa y palabra profética: el profetismo en el judaísmo post-exílico}

Para entender esta polémica convendría quizás remontarse a un contexto histórico más amplio. En la época de Jesús ya se había desarrollado toda una teología de la Ley y al mismo tiempo se había consolidado un estamento de peritos a su servicio ${ }^{12}$. Baste recordar las imágenes con que se refiere a ella la

9. Ibid., p. 32 .

10. Ibíd., pp. 40-42.

11. Ibíd., pp. 43s.

12. A propósito de esta teología explicitada y desarrollada después en los escritos rabínicos dice J. Bonsirven: "Una de las impresiones más netas que deja la familiaridad con la literatura rabínica es el lugar enorme que ocupa en ella la Torá: en infinidad de textos bíblicos se descubren alusiones a la Torá, se la ve figurada en multitud de rasgos y símbolos, es el objeto de una preocupación constante, de un culto fiel; de entre las máximas tradicionales que fueron consideradas dignas de recuerdo y conservación, Pirqé Abot, el mayor número se refieren a la Ley y su estudio. Un cristiano tiene en- 
literatura rabínica de los primeros siglos. La designan como fuerza, agua, vino, aceite, miel, árbol de la vida, fuego, curación y vida, lluvia, luz de Dios, paz, bálsamo de vida, etc. Según ellos, la Ley es del cielo, propiedad de Dios, instrumento de la creación, contiene el eón futuro, está por encima de la realeza y del sacerdocio, es uno de los tres fundamentos del mundo, es inmutable, se la puede explicar pero sin añadir ni quitar nada, etc. Junto con la Ley se coloca también la tradición oral: hay dos Torá, la escrita y la oral; en efecto, la Torá había sido entregada con todas las minuciosidades rabínicas. Hay que dirigir todo hacia la Torá, más aún que hacia el templo. Hacer un prosélito es conducirlo a la Torá ${ }^{13}$.

Evidentemente, la Torá ha venido a ocupar el centro del universo religioso de Israel, a constituir el fundamento mismo de todas sus instituciones y a ostentar la mediación absoluta con la divinidad. Es la culminación de un proceso que se remonta a siglos atrás y que es el resultado de múltiples circunstancias.

En tiempos de Josías (641-609 a. C.) se realiza un vasto plan de reformas. El momento culminante lo señala el descubrimiento y la proclamación del texto de la Ley (a. 622). Se trata de una versión anterior, menos desarrollada, del actual Deuteronomio ${ }^{14}$. Es patente el misterio, casi teofánico, con que se describe el descubrimiento del rollo y luego su proclamación pública (2 Re 22, 8-23,3).

Durante el exilio (598-538 a. C.) desaparecen, al menos en su funcionalidad, instituciones clave como la monarquía. Tampoco el sacerdocio puede tener, dadas las peculiaridades del exilio, el mismo papel. Este período que conoce el liderazgo de grandes profetas, como el deutero Isaías y Ezequiel, alumbra un período nuevo en que la Ley va convirtiéndose poco a poco en el distintivo por excelencia de Israel en medio de los demás pueblos (Dt 4, 6-8). Se va desarrollando consecuentemente una teología de la Ley. El deuteronomista hace de esta teología la clave de lectura de la historia de Israel. Después del desastre de la caída de Jerusalén y del exilio se hacía necesario explicar lo acaecido. Define la relación entre Dios y el pueblo como una alianza, pero no se entiende con

seguida la impresión de que para los rabinos la Torá es, en gran parte, lo que Cristo es para él. Este primado se advierte de manera significativa en la dinámica que poco a poco sustituye la Torá a la Sabiduría a la que dota de todas las funciones de esta creatura de Dios primera y privilegiada. Esta dinámica marca un hito en la evolución del judaísmo: la victoria progresiva, definitiva después, del nomismo, de la nomocracia”, Le Judaisme Palestinien au temps de Jésus-Christ, 1, La Théologie Dogmatique, París, 1934, pp. 248 y ss.; cfr. también H. Küng, Judaísmo. Pasado, presente, futuro, Madrid, 1993, pp. 132-137.

13 Cfr. J. Bonsirven, Textes Rabbiniques des deux premiers siècles chrétiens, óp. cit., pp. 776 y ss.

14. Cfr. L. A. Schökel y varios, Libros Sagrados, Reyes, Madrid, 1973, p. 207; J. Blenkinsopp, El Pentateuco, Estella, 1999, pp. 270-277. 
ello el acto de hacer alianza — según el sentido original—, sino más bien la permanente regulación de la relación Dios/pueblo según el patrón de la Ley. Aún más, equipara los términos de Alianza y Ley ${ }^{15}$. Desde esta perspectiva hay que entender la idea de retribución que atraviesa la obra del deuteronomista.

El papel identitario que adquiere en la conciencia de Israel el conjunto de libros sagrados (entre ellos, sobre todo la Torá) queda registrado en el prólogo del Eclesiástico (principios del siglo II a. C.): "Muchos y grandes dones hemos recibido de la Ley y los Profetas y los demás que los siguieron, por los que Israel merece alabanza de sabio e instruido. Y como no basta que sus lectores aprendan sino que deben ser capaces de ayudar a los de fuera, de palabra y por escrito, mi abuelo Jesús, después de dedicarse enteramente a leer la Ley y los Profetas y los restantes libros paternos y de adquirir un buen dominio de ellos, se decidió a componer por su cuenta". Existe ya un cuerpo literario suficientemente sistematizado que condensa, y en el que se reconoce, la sabiduría propia y distintiva de Israel $^{16}$.

Se observa entretanto un fenómeno de singular importancia: el agotamiento de la profecía del que ya algunos textos se hacen eco: "Tribulación tan grande no ha sufrido Israel desde los tiempos en que dejaron de aparecer profetas" (1 M 9, 27; cfr. 4, 46; 14, 41). Idéntica constatación harán los escritos rabínicos: Sotá, 48b; Yomá, 9b; Sanh, 11 (bar.).

Se impone una pregunta: ¿qué ha pasado $?^{17}$. Es verdad que en el inmediato post-exilio se registra un fracaso de la profecía salvífica en el sentido de que muchas de las promesas que hincharon las esperanzas de los retornados quedaron incumplidas y que esto provocó una corrección de las previsiones proféticas y una cierta marginación social del mismo profetismo y la apertura a la escato-

15. M. Noth, The Deuteronomistic History, Journal for the Study of the Old Testament, Supplement Series 15, Sheffield, 1981, p. 90.

16. A esto indudablemente ha contribuido de una forma decisiva, como queda dicho, la experiencia del exilio con la quiebra de las otras instituciones que articulaban la vida de la comunidad, a lo que se añadiría después, la defensa de las tradiciones patrias como reacción a la política de helenización emprendida por los seléucidas y que provocará la insurrección macabea en tiempos de Antíoco IV Epifanes (175-163 a. C.), y, aunque en otra dirección, el peso, cada vez más poderoso, de la comunidad judía de Alejandría que, a la sombra de la actividad literaria de la Biblioteca, se esfuerza en hacer valer y desarrollar con orgullo su propio patrimonio literario como lo muestra la carta de Pseudo Aristeas (siglo II a. C.).

17. No se pueden dejar de poner en relación los dos hechos. Para una comprensión del fenómeno profético en la versión específica de Israel, como institución característica de su universo religioso (Am 2,11), tanto o más instructivo que el estudio de su nacimiento, es el de su ocaso. 
logía ${ }^{18}$; pero decisivos fueron, sobre todo, los nuevos equilibrios institucionales en los que se reconstruyó el universo religioso de Israel y cuya piedra angular fue el libro de la Ley, y la centralidad de lo escrito.

El libro del Deuteronomio pone repetidamente en boca de Moisés una apelación a la escucha de la palabra: "Escucha, Israel" (Dt 5, 1; 6, 4; 9, 1). La fórmula es profética, pero aquí se trata de escuchar la proclamación leída de la Ley escrita (Dt 17,18-19) y, más específicamente, de los mandamientos y decretos $(4,45 ; 5,1 ; 6,1 ; 7,11$ y passim). Pronto se hará la identificación de la Sabiduría primordial no solo con la Ley, sino también con el libro de la Ley: "Todo esto (la Sabiduría personificada) es el libro de la alianza del Dios Altísimo, la Ley que nos prescribió Moisés como herencia para las asambleas de Jacob" (Eclo 24, 23; cfr. Bar 4, 1) ${ }^{19}$.

El profeta u hombre de la palabra era el mediador nato entre el Dios que habla y su pueblo ( $c f r$. Jer 1, 7; Is 6, 6-9, etc.). La misión del profeta era captar los signos de los tiempos, leerlos a impulso del espíritu de Dios y hacer actuales las condiciones del pacto de la alianza. Era la caja de resonancia de Dios que se revelaba en la historia y que hablaba a través de los acontecimientos ${ }^{20}$.

18. Cfr. a este respecto R. Albertz, Historia de la religión de Israel en tiempos del Antiguo Testamento, 2. Desde el exilio hasta la época de los Macabeos, Madrid, 1999, pp. 594-600.

19. Para la polémica subyacente en el llamado prólogo del evangelio de Juan (Jn 1, 1-18) con relación a una conceptualización semejante $c f r$. mi artículo J. Barreto, "Contexto literario de Jn 1, 1-18", Fortunatae 13 (2002) 45-64. Para el significado y alcance de la espiritualidad basada en la Torá tal como se refleja en algunos salmos tardíos, Sal $1 ; 19 ; 119$, "en todos estos pasajes, la Torá ocupa el puesto del 'rostro de Dios"': $c f r$. R. Albertz, óp. cit., pp. 770-802.

20. Según las doctores judíos, lo esencial de ministerio profético es "anunciar el futuro, revelar los secretos de los corazones y también de cada una de sus partes" (Mekh, 16, 31). Pero, como nota J. Bonsirven, esta noción "es una reducción de la misión del profeta, que era ante todo el encargado de transmitir la palabra de Dios, palabra que se refería más a menudo al presente que al futuro": Le Judaisme Palestinien au temps de Jésus-Christ, óp. cit., p. 256. En este contexto, la comunicación de la palabra actual y viva de Dios quedará reservada a la bat qôl. Pero las características de ésta muestran una sustancial diferencia con el fenómeno profético. Es una palabra, una voz, que viene del cielo directamente, no hay mediación humana, y, cuando la hay, se trata de una palabra de hombre pero no de una palabra verdaderamente humana: una palabra inesperada de un hombre, o la voz de un niño que recita la Escritura pueden convertirse para el que escucha en "hija de la palabra". No interesa la participación humana del hablante sino su calidad de instrumento, como pueden ser en otros casos los fenómenos atmosféricos, el trueno, etc.; es puntual, sucede en cada caso, no está ligada a la misión de un hombre. Su juicio se refiere a la interpretación de la Ley, pero es situacional, y su directriz nunca llega a ser un $h^{a} l a \hat{k} a \hat{h}$ de valor general; $c f r$. O. Betz, "phônê", II Rabbinisches Schrifttum, TWNT, IX, pp. 280-283. 
Una vez que la palabra de Dios se totaliza en la Ley escrita y en la tradición oral codificada ${ }^{21}$ identificándose con un cuerpo literario, esta palabra se estatiza. Dentro de este nuevo equilibrio Dios ya no es "el que habla", sino más bien "el que habló". Su palabra, así objetivada y estatizada, tiende a considerarse atemporal. Los antiguos mediadores del Dios hablante, los profetas, ya no encuentran espacio en esta nueva correlación ${ }^{22}$. Ahora el mediador entre la palabra escrita del Dios que habló y el pueblo es necesariamente el entendido, el perito de la Ley, el maestro.

Los rabinos se harán eco del conflicto posible entre ley escrita y profecía ya insinuado en Jer 2, 8; 8, 8. Lo resuelven a favor de la Ley: todo lo que los profetas dijeron fue ya comunicado a Moisés, igual que toda la Escritura y la Ley oral ${ }^{23}$.

Esta inflexión se hace notar ya en el Deuteronomio. La única vez que se menciona la profecía es, por una parte, para poner en guardia contra los falsos profetas y, por otra, para anunciar que el Señor habría de suscitar un profeta como Moisés (Dt 18, 9-22). El texto sirve de disuasión para el ministerio profético, no solo porque pone el listón muy alto y lo centra en una figura única - como Moisés - proyectada hacia un futuro ideal, sino porque se traza un perfil muy concreto: el Moisés del Deuteronomio es el que proclama la Ley de Dios escrita.

La consecuencia más grave de este proceso es que al convertirse la ley escrita y la tradición oral en mediación absoluta entre Dios y el hombre, siendo esa ley eterna e inmutable ${ }^{24}$, la vida cambiante y el hombre mismo quedan al margen. Se altera así el equilibrio original de la fe de Israel formulado ya en sus credos más arcaicos (Dt 26, 5-9; 6, 21-23; Jos 24, 2-13): una expresión de fe en la acción del Señor en la historia del pueblo; era profesión de fe y proclamación de la propia historia y más concretamente, de la elección y liberación. Era en esta experiencia de liberación donde Dios se manifestaba sobremanera (Is 52, 6).

En el nuevo equilibrio Dios es sobre todo el que impone su voluntad ya codificada en una ley inmutable. El hombre ha de someterse a ella y el diálogo con

21. La Ley oral gozaba de una autoridad divina igual a la de la Ley escrita. Provenía de Moisés y había sido trasmitida en sucesión ininterrumpida; cfr. J. Bonsirven, Le Judaisme Palestinien au temps de Jésus-Chist, óp. cit., pp. 270-272.

22. Sociológicamente, el profetismo se refugia en las clases desfavorecidas por la crisis económica, social y política en la que entra el pueblo en el inmediato post-exilio, y se orienta hacia una profecía escatológica, que refleja ya un pesimismo en las posibilidades históricas de Israel. Cfr. al respecto R. Albertz, óp. cit., pp. 677-682.

23. Cfr. Abot, 1, 1; Mekh, 15,26; SNum. 15, 23 (111); Megil. 19b (R Jahasmn); Cant R 5, 14; Benak 5e (R. Simeón b. Laquis); Jubil, 1, 4; 4 Esd. 14, 5. Textos citados por J. Bonsirven, óp. cit., 1, 257.

24. "Su principal propiedad es ser eterna e inmutable... Incluso en los tiempos mesiánicos y en la vida del más allá la Ley subsistirá, y la gran dicha de los bienaventurados será poderla estudiar bajo la dirección de Dios: todos rabinos y rabinos celestes", ibíd., pp. I, 301s. 
Dios se reduce a simple obediencia. La palabra de Dios toca cada vez menos la historia del hombre, si no es para llamarlo a una fidelidad minuciosa y puntual de todas las observancias legales.

En la polémica relativa al primer mandamiento de la Ley y al sábado, en los Evangelios, lo que está en juego es justamente este papel atribuido a la Ley como mediación absoluta, que Jesús no acepta. Jesús representa, en este sentido, la recuperación del espíritu profético ${ }^{25}$.

Lo importante de esos pasajes es que revelan una nueva concepción de la relación Dios/hombre, que es la que realmente está en litigio. Podemos focalizar el problema, aun a riesgo de simplificarlo, en estos términos: la soberanía o reinado de Dios, ¿se expresa solo o principalmente en la imposición de su voluntad normativa que, además, ya ha sido completamente expuesta y fijada en la Ley? ¿O más bien se manifiesta como presencia salvadora y liberadora que sale al encuentro del hombre en sus situaciones de postración física, moral y social?

En otras palabras, ¿el reinado de Dios se expresa en el ejercicio de su dominio y tiene su instrumento privilegiado en la aplicación de la Ley como expresión de su voluntad inapelable, o, más bien se expresa en el ejercicio de su poder creador y rehabilitador?

\subsection{Jesús y la Ley}

\subsubsection{El mandamiento más importante}

El pasaje que se refiere a la discusión acerca del mandamiento principal de la Ley es común a los sinópticos (Mc 12, 28-34; Mt 22, 34-40; Lc 10, 25-28; cfr. Jn 13, 34-35), aunque con matizaciones diversas: Marcos y Mateo lo sitúan dentro de una serie de cuestiones polémicas dirigidas a Jesús o que Jesús dirige a los distintos grupos (fariseos y saduceos) y que marcan el clímax del enfrentamiento final que precipita el arresto y la condena de Jesús. Lucas, por su parte, con una perspectiva diferente, lo refiere en el contexto de la misión de los setenta.

Tanto Marcos como Mateo y Lucas tienen en común el establecimiento de la prioridad, no de uno, sino de dos mandamientos: el del amor a Dios y el del amor al prójimo.

Los rabinos contaban un sinfín de mandamientos en la Ley; para ser más exactos, 613: 248 positivos y 365 negativos. Se dividían también, según la materia, en pequeños y grandes. Pero partiendo de la concepción central de la Ley como expresión de la Palabra eterna e inmutable de Dios, los rabinos recalcaban

25. Cfr. J. Bonsirven, Le Règne de Dieu, óp. cit., pp. 74-78. 
la pluralidad de mandamientos cayendo en una moral atomística, según la cual todos los mandamientos, desde el más pequeño hasta el más grande, tienen igual importancia ${ }^{26}$.

En Marcos y Mateo la pregunta por el mandamiento más importante (en singular) recibe como respuesta la cita de dos mandamientos cuya prioridad sobre los demás se pone de manifiesto.

En Marcos, contrariamente a Mateo y Lucas, el letrado que hace la pregunta no la plantea con ánimo hostil distanciándose así de la animosidad que muestran los otros interlocutores que rodean a Jesús ${ }^{27}$.

El planteamiento de su pregunta es también peculiar: “¿Qué clase de mandato tiene prioridad entre todas las cosas?" (Mc 12, 28) $)^{28}$, y creo que merece un examen más atento.

El horizonte de comparación del escriba no es solo la serie de mandatos, sino el conjunto de la actividad que el hombre puede desplegar para agradar a Dios: "entre todas las cosas", dice.

Si esta apreciación es correcta, el letrado no preguntaría tanto por el mandato como formulación legal en sí en comparación con otros mandatos, cuanto por la valoración de la actividad que el mandato exigiría comparándola con las otras actividades que el hombre pudiera hacer para agradar a Dios. De hecho, cuando muestra su conformidad con la respuesta de Jesús, no hace referencia a la prioridad del mandato sobre los otros sino al valor mismo de la actividad a la que los mandatos se refieren: “¡Muy bien, Maestro! Es verdad lo que has dicho... que amarlo (al Señor)... y amar al prójimo vale más que todos los holocaustos y sacrificios" (Mc 12, 32). En otras palabras, no es el mandato solo el que confiere valor a lo mandado; la importancia del mandato está en relación con la importancia de lo mandado. Y ese criterio es exterior a la Ley.

De hecho, en esta segunda comparación del letrado: "más que todos los holocaustos y sacrificios", resuena un tema característico de los profetas que radican la piedad de Israel más en el conocimiento de Dios y la realización de la justicia que en las prácticas rituales que sin aquellos estarían vacías. Los

26. Cfr. P. Bonnard, Evangelio según San Mateo, Madrid, $1983^{2}$, pp. 486 y ss.

27. Cfr. sobre esta perícopa el excelente comentario de J. Mateos y F. Camacho, El Evangelio de Marcos, III, Córdoba, 2008, pp. 231-248.

28. Creo que esta traducción responde más al tenor del texto griego y da razón tanto del adjetivo poia que indica calidad ("qué clase de mandamiento") y del incómodo pantôn, interpretado como neutro plural ("entre todas las cosas") que no puede concordar con el femenino entolê. Esta traducción, además de no forzar la gramática del texto, en mi opinión se ajusta bien al contexto según la explicación que expongo. Para otras opiniones $c f r$. J. Mateos y F. Camacho, óp. cit., p. 232. 
intereses de Dios y del hombre están tan asociados que sin la realización de la justicia con el hombre no hay posibilidad de agradar a Dios (Am 5, 21-25; Os 6, 6; Jer 7, 22-26).

La apreciación positiva que hace Jesús de su interlocutor: "no estás lejos del Reinado de Dios" (Mc 12,34) es coherente con este planteamiento ${ }^{29}$.

En Mateo $(22,34-40)$ se señalan diferencias con respecto a Marcos. En primer lugar, el carácter polémico de la pregunta: "Los fariseos, al enterarse de que Jesús había tapado la boca a los saduceos, formaron grupo, y uno de ellos, que era jurista, le preguntó para ponerlo a prueba" (Mt 22, 34s).

El letrado pregunta por el mandamiento principal ${ }^{30}$ de la Ley: "Maestro, ¿cuál es el mandamiento principal de la Ley?" (Mt 22, 36). Su horizonte, pues, es interior a la Ley. "Él le contestó: Amarás al Señor tu Dios con toda tu corazón, con toda tu alma, con toda tu mente. Este es el mandamiento principal y el primero, pero hay un segundo no menos importante: Amarás a tu prójimo como a ti mismo. De estos dos mandamientos penden la Ley entera y los Profetas" (Mt 22, 34-40).

También en la respuesta de Jesús se añade una precisión con respecto a la versión marcana. No yuxtapone simplemente los dos mandamientos, sino que los enlaza: "Pero hay un segundo no menos importante" ${ }^{31}$. La novedad de la formulación de Jesús respecto a estos dos mandamientos es que, en cierto sentido, los equipara. Notemos a este propósito la fuerza que en el contexto polémico adquiere la adversativa ("pero hay..."), que reclama la atención sobre la importante precisión que sigue.

Jesús, por otra parte, insiste en que toda la Ley y los Profetas penden (literalmente: "están colgados", gr. krematai) de estos dos mandamientos. Por tanto no son dos, aunque los más importantes, dentro de una serie homogénea de mandamientos. La respuesta de Jesús desplaza el problema de lo cuantitativo a lo cualitativo: el principal para Jesús es el fundamental, o mejor, los fundamentales, puesto que son dos inseparables; Jesús los propone como clave interpretativa de toda la Ley.

El contexto en que esta polémica se presenta en Lucas $(10,25-37)$ es notablemente distinto al de Marcos y Mateo. Sigue a la misión universal de los

29. Le falta pasar del planteamiento teórico a la realización práctica. $C f r$. al respecto J. Mateos y F. Camacho, óp. cit., pp. 245 y ss.

30. Gr. megalê por megistê, positivo por superlartivo por influencia del hebreo. Cfr. J. H. Moulton y N. Turner, A Grammar of New Testament Greek, 111; Sintax, Edinburgh, 1963, p. 31.

31. Gr. deutera de homoia autê. No se indica un rango de segundo grado, sino un segundo mandamiento tan importante. Cfr. P. Bonnard, óp. cit., p. 489. 
setenta y dos, en la que se contiene el rechazo de las ciudades arrogantes $(10,1-20)$ y la revelación a los sencillos $(10,21-24)$.

Conviene con Mateo en que el perito de la ley hace la pregunta con intención de ponerlo a prueba, pero el contenido de la pregunta no se refiere directamente a la Ley sino a lo que hay "que hacer para heredar la vida definitiva" (Lc 10, 25). Jesús hace, a su vez, una contra-pregunta (y en esto se distingue también de Marcos y Mateo): “¿Qué está escrito en la Ley? ¿Cómo es eso que lees?" $(10,26)$. Habla de escritura y de lectura, y, al perito de la ley (nomikós) le invita a ver lo que está en la Ley (en tô nómô). No sin cierta ironía, como veremos, Jesús se sitúa en el mismo terreno de su adversario ${ }^{32}$.

Lucas hace formular al perito lo que en Marcos y Lucas constituye la respuesta que el mismo Jesús da a la pregunta de cuál es el mandamiento principal: "Éste contestó: Amarás al Señor tu Dios con todo tu corazón, con toda tu alma, con todas tus fuerzas y con toda tu mente. Y a tu prójimo como a ti mismo" (Lc 10, 27).

El foco de atención de Lucas no es tanto determinar cuál es el mandamiento principal (aquí clarísimamente los dos de Marcos y Mateo ya son uno) ${ }^{33}$, lo que se da por supuesto, sino más bien cómo entenderlo. Y es en el cómo donde se centra la segunda pregunta con que el perito se justifica: "Y ¿quién es mi prójimo?" (Lc 10, 20).

La respuesta de Jesús pone al perito de la Ley ante un hecho que en su formulación no podía dejar de tener carácter provocador: lo obliga a ser juez entre unos agentes del culto del templo de Jerusalén, sacerdote y levita, y, entre un samaritano, para un judío, por definición cismático e idólatra.

La pregunta tiene como objeto aclarar quién era el prójimo, próximo (gr. plêsíon con el mismo doble sentido que en español). Jesús le muestra, en primer lugar, un "hombre" (ánthrôpos tis), sin calificaciones étnicas, religiosas o éticas, del que el único rasgo pertinente en el relato es que ha sido despojado y reducido al límite de su vida por unos bandidos (Lc 10, 30); en

32. Para la estructura académica del relato, cfr. F. Bovon, El evangelio según San Lucas II (Lc 9, 51-14, 35), Salamanca, 2002, pp. 110-113.

33. La combinación de Dt 6, 5 y Lev 19, 8, que encontramos ya en Marcos y Mateo, aparece, al contrario que en ellos, sin ninguna transición que distinga entre uno y otro mandamiento, con lo que se obtiene una única formulación. No nos parece que la combinación de los dos textos, común a los sinópticos, sea específicamente cristiana. Está atestiguada en los Testamentos de los XII Patriarcas (TestBenj 3, 3-4; TestDan 5, 3; TestZab 5, 1; TestIss 5, 1; 7,6), si bien depende del influjo cristiano que se quiera atribuir a dicho texto. Si fuera así, difícilmente se pondría en boca del perito de la Ley, al que además se le reconoce la intención de tentarlo, una tal formulación. $C f r$. al respecto F. Bovon, óp. cit., p. 115, n. 17. 
segundo lugar, tres miradas a ese "hombre", las del sacerdote y levita, por una parte, y la del samaritano, por otra (Lc 10, 31-33); y, por último, dos movimientos opuestos con respecto al mismo, de alejamiento, el del sacerdote y del levita, ("dio un rodeo y pasó de largo" idéntico en los dos casos), de acercamiento, el del samaritano ("se acercó a él") (Lc 10, 34).

No se dicen las razones por las que el sacerdote y el levita se alejaron del hombre. Podían invocar leyes de pureza ritual como Lev 5, 2-3; 21, 1-3; Nm 5, 2; 19, 1-22; Ez 44, 25-27. Sí en cambio se expresa por qué se acerca el samaritano; éste no invoca en su actuación un texto de la Ley (los samaritanos también la tenían), obedece a un impulso interior: "al verlo se conmovió" (gr. esplankhnisthê). Este verbo marca el centro de gravedad de la parábola. Es usado en el Nuevo Testamento sólo de Jesús: Mt 9, 36; 14, 14; 15, 32: 20, 34; Mc 1,$41 ; 6,34 ; 8,2 ; 9,22 ; \mathrm{Lc} 7,13 ; \mathrm{y}$ del Padre en parábolas que se refieren a él: Mt 18, 27; Lc 15, 20; cfr. Lc 1, 78. Responde al hebreo rhm: Ex 33, 19; que en forma adjetival es definitorio de Dios: Ex 34, 6; Dt 4, 31; Jl 2, 13; Jon 4, 2; Sal 78, 38; 86,$15 ; 103,8 ; 111,4 ; 112,4 ; 145,8$; Neh 9,$17 ; 9,31 ; 2$ Cro $39,9^{34}$.

El Jesús de Lucas que había encarado al perito de la Ley con una pregunta acerca de lo escrito en ella, cierra ahora su exposición con otra: "¿Quién de estos tres se hizo prójimo del que cayó en manos de los bandidos?” (Lc 10, 36).

El jurista se las ha de ver no sólo con la interpretación de la letra de la Ley, sino con la interpretación de los signos de Dios en la vida de los hombres. La compasión de un hombre es normativa para el entendido de la Ley: "Pues anda, haz tú lo mismo" $(10,37)$.

La contraposición de los agentes de culto y el samaritano constituye una ejemplificación extrema de lo que en Marcos entendió el letrado: que el amor a Dios y al prójimo vale más que los holocaustos y sacrificios (Mc 12, 33). Pero aquí se insinúa algo más: el samaritano, con todo lo que para un judío representaba, es la prueba de que el verdadero culto es el ejercicio de la compasión y que la obediencia radical consiste en tener los sentimientos de Dios hacia el hombre, cualquier hombre, sufriente. Y eso no es ley sino espíritu, dinamismo que genera un movimiento de encuentro, que emana de Dios mismo como su fuente, que es anterior y fundamento de la ley y la desborda.

En Juan no se encuentra un pasaje paralelo al de los sinópticos, pero sí se aborda el tema del mandamiento principal. En el llamado prólogo Jn 1, 1-18,

34. El verbo griego denominativo del sustantivo splankhnon ("entrañas", "vísceras") ha sustituido en la literatura intertestamentaria (Test. XII) a oiktirmós, oikteírô, oiktírmôn de los LXX y constituye una nueva traducción del hebreo rahamim, riham, rahum; este mismo uso lo continúa el NT. Cfr. H. Köster, "splankhnon...", B. Die Wortgruppe in den spätjüdischen Schriften, TWNT, VII, pp. 552 y ss. 
se expresa el credo de la comunidad. El texto se estructura como contraposición y réplica al esquema sapiencial de la revelación de la Sabiduría que se había hecho canónico en el judaísmo post-exílico. Este esquema comprendía los siguientes elementos ${ }^{35}$ :

(a) La Sabiduría en su relación con Dios, como criatura primigenia.

(b) La Sabiduría presente en la obra creadora.

(c) La Sabiduría participada por el hombre y dada en especial a Israel.

(d) La Sabiduría identificada con la norma ética y finalmente con el libro de la Ley.

(e) La Sabiduría causa de la vida del hombre.

Este estereotipo literario que expone la comprensión de la Sabiduría se encuentra en multitud de textos ( $c f r$. Eclo 24, 1-24; Bar 3, 22-4, 4).

Juan adopta ese esquema, pero, en contraposición con la concepción judía, lo modifica sobre todo en dos puntos: la Sabiduría es la Palabra, y la última y definitiva manifestación histórica de la misma no es el libro de la Ley sino la humanidad débil, carne, de Jesús en la que resplandece la gloria del Padre: amor y fidelidad (Jn 1, 14). Si la Ley se dio por medio de Moisés, el amor y fidelidad se han hecho realidad por medio de Jesús Mesías (Jn 1, 17). En consecuencia es Jesús como expresión del amor del Padre la concreción histórica más cabal de su Palabra, la expresión perfecta del Padre (Jn 14, 7-11). Seguirle a él, recibiendo de su plenitud, es amar como él $(1,16)$. Y esto es lo que se formula en el contexto de la cena, como mandato constitutivo y distintivo de la comunidad. Se trata del mandamiento nuevo: "Les doy un mandamiento nuevo: que se amen los unos a los otros; igual que yo les he amado, ámense también unos a otros. En esto conocerán todos que ustedes son discípulos míos: en que se tienen amor entre ustedes" (Jn 13, 34) ${ }^{36}$.

\subsubsection{El sentido de la Ley: la cuestión del sábado}

Las controversias que registran los evangelios en torno al sábado ejemplifican en un caso emblemático su postura ante la Ley en general.

"Sucedió que un sábado atravesaba él por los sembrados, y sus discípulos empezaron a arrancar espigas haciendo camino. Los fariseos le dijeron: ¡Oye!, ¿cómo hacen en sábado lo que no está permitido? Él les replicó: ¿No han leído nunca lo que hizo David cuando tuvo necesidad y sintió hambre él y

35. Para un desarrollo más amplio del tema, ver J. Barreto, "Contexto literario de Jn 1, 1-18", óp. cit.; también J. Mateos y J. Barreto, El evangelio de Juan. Análisis lingüístico y comentario exegético, Madrid, 1992 ${ }^{3}$, pp. 39-85.

36. J. Mateos y J. Barreto, óp. cit., pp. 617-622. 
los que estaban con él? ¿Cómo entró en la casa de Dios, en tiempos del sumo sacerdote Abiatar, y comió de los panes de la ofrenda que no está permitido comer más que a los sacerdotes y les dio también a sus compañeros? Y añadió: El sábado existió por el hombre y no el hombre por el sábado" (Mc 2, 23-28; cfr. Mt 12, 1-8; Lc 6, 1-5).

No se trata simplemente de casuística legal ni de un incidente entre dos corrientes de opinión sobre la aplicación de la Ley. El problema es mucho más radical: el sentido mismo de la Ley y, con ello, el modo de la relación Dios/ hombre.

Frente al reproche de los fariseos de que los discípulos de Jesús violan el sábado (precepto inmutable como inmutable era Dios mismo y su Ley, objetivación de su voluntad), Jesús trae a colación el ejemplo de David (1 Sam 21, 1-6) referido a otro precepto sobre los panes de la proposición ( $\operatorname{Lv} 24,5-9$ ), para concluir que la Ley, toda ley, es para el hombre y no el hombre para la ley $\left(\right.$ Mc 2, 27) ${ }^{37}$.

Este principio vuelca la perspectiva de los legalistas a quienes sonaba a blasfemia. De hecho, acusan a Jesús de blasfemo a propósito de lo que ellos llamaban violación del sábado. Cambiarlo era cambiar la voluntad divina expresada en el precepto y esto equivalía a hacerse igual a Dios (Mc 3, 6; cfr. Jn 5, 17s). Su razonamiento era éste: la Ley contiene y expresa la voluntad divina y ésta, escrita, es inmutable y sólo Dios puede cambiarla; la Ley es expresión de Dios mismo y Dios no es para el hombre sino el hombre para Dios.

Los fariseos plantean, pues, la cuestión desde la prescripción de la Ley: no es lícito (Ex 19, 8-11; Lev 23, 3-4). Es su único criterio regulador de la conducta humana. Es exterior al hombre, proviene de Dios y, por consiguiente, es irreformable.

La respuesta de Jesús apela, sin embargo, a otro criterio: "Tuvo necesidad y sintió hambre" (Mc 2, 25). La necesidad (gr. khreia) es un criterio inherente al hombre, es variable, histórica como el hombre. La necesidad hace lícito que el hombre participe de los panes ofrecidos ya a Dios y reservados a los sacerdotes. La necesidad cambia el destino del pan.

El episodio de la curación del brazo (Mc 3, 1-6; cfr. Mt 12, 14-9; Lc 6, 6-11) que sigue inmediatamente hay que leerlo en relación con el anterior. Parece extraño a primera vista que Jesús recurra a un principio tan general: “¿Es lícito en sábado hacer el bien o hacer el mal?" (Mc 3, 4). Este principio, por evidente, resulta ocioso. Pero de mal y bien los fariseos tenían una definición estricta-

37. Más tarde los discípulos tendrán necesidad de decir que no sólo Jesús ha reinterpretado la Ley y el sábado, sino que el sábado mismo ha quedado abrogado (Mc 2, 28). Para la historia de la redacción, $c f r$. V. Taylor, óp. cit., pp. 245s. 
mente jurídica; hubieran respondido: el bien es lo que manda la Ley, el mal, lo que prohíbe.

Pero Jesús se apresura a añadir en paralelo con lo anterior: “(es lícito) salvar una vida (bien) o matar (mal)?". El bien y el mal al que Jesús se refiere no viene configurado por la Ley, sino por la vida o la muerte del hombre entero.

El haber recurrido al principio más general quiere indicar que es válido siempre y anterior a cualquier otro. La solución intermedia de aplazar la curación en favor de la salvaguarda del sábado no tiene sentido para Jesús. La necesidad del hombre es normativa cuando y donde se presente. La Ley no puede ser obstáculo porque ha de estar al servicio del hombre.

El sábado es un tiempo consagrado a Dios, pero no hay para Jesús un tiempo de Dios distinto del tiempo del hombre. El tiempo que se consagra a Dios no se hurta al hombre en su necesidad, como tampoco el pan que se le ha ofrecido. Dios baja al tiempo del hombre y su presencia es activa y operante. La misericordia consagra el tiempo del hombre. Así lo entiende Juan en circunstancias paralelas y en coherencia con su comprensión de la figura de Jesús como la expresión de la Palabra-Sabiduría creadora: "Mi Padre hasta el presente sigue trabajando y yo también trabajo" (Jn 5, 17)

Para Jesús la Ley tiene sentido en función del mismo hombre, está a su servicio. La Ley no está encerrada en sí misma. Está abierta, como el mismo amor de Dios, hacia el hombre y sus necesidades cambiantes. Dios se define por su amor misericordioso, y la Ley más radical y universal es esa misma actitud divina hacia el hombre. Ella constituye el fundamento mismo de la Ley; anterior a ésta, la fundamenta y la desborda. Es actual y viva, la clave de interpretación no solo de la Ley, sino del hombre y de Dios mismo que así se revela. Por ello concluye Mateo, en su versión de este mismo pasaje, recordando las palabras de Oseas: "Si hubieran comprendido lo que significa aquello de: Misericordia quiero y no sacrificios (Os 6, 6), no condenarían a los que no tienen culpa" (Mt 12,7).

Para Jesús el problema de la Ley y su aplicación es un problema de comprensión de Dios, un problema teológico.

\subsubsection{El código de la alianza mesiánica}

Jesús ha sido presentado como el nuevo legislador: desde la montaña, réplica del Sinaí (Mt 5, 1), Jesús propone su Ley que se condensa en las Bienaventuranzas (Mt 5,2-10) y que es réplica de la antigua Ley ${ }^{39}$. Es evidente el aliento

38. Para el tema de la actitud de Jesús ante el sábado en Jn 5; 9, curación del paralítico y del ciego, remito a J. Barreto, "Señales y discernimiento en el evangelio de Juan", Revista Latinoamericana de Teología 40 (1997) 41-59.

39. Ver el excelente comentario de A. Maggi, Las Bienaventuranzas, Córdoba, 2001. 
profético de toda la sección que comienza no exponiendo mandamientos, sino proclamando bienaventuranzas para los pobres, excluidos y perseguidos.

El Sermón de la Montaña (Mt 5, 11 - 7, 28) explicita el contenido de las bienaventuranzas. Después de exponer el núcleo de su Ley, explica cuál es la relación que mantiene con toda la antigua economía (Ley y Profetas): "No piensen ustedes que he venido a echar abajo la Ley ni los Profetas. No he venido a echar abajo sino a dar cumplimiento" (Mt 5, 17). "Echar abajo" (gr. katalyô, "disolver", "demoler", "derribar") en Mateo se emplea sólo de la destrucción del templo $(24,2 ; 26.61 ; 27,40)$. En el Nuevo Testamento no tiene sentido legal, y aquí el complemento "la Ley y los Profetas", es decir, todo el Antiguo Testamento, excluye el sentido de "derogar" como si se tratase de preceptos legales. En el texto este verbo se opone a otro, "dar cumplimiento" (gr. plêrôsai), característico de Mateo para indicar el cumplimiento en Jesús de todas las expectativas mesiánicas $(1,22: 2,15.17 ; 4,14)$.

Jesús, pues, no viene a anular la antigua economía sino que toda ella, en Jesús, llega a la plenitud; todas las antiguas esperanzas en ella contenidas se "realizarán" puntualmente (Mt 5, 18) (gr. génêtai, que no se refiere al cumplimiento de una norma, sino a la realización de algo $)^{40}$.

Aclarada la relación de la nueva economía con la antigua, se habla del valor de los nuevos mandamientos, los contenidos en este código: "Por tanto, el que se exima de uno solo de esos mandamientos mínimos será llamado mínimo en el reino de Dios" (Mt 5, 19); "esos" (gr. toutôn, anafórico) no puede referirse a los mandamientos de la Ley (si se refiriese a "una sola letra o a un solo acento de la Ley", debería decir autoû).

La fidelidad exigida está en relación con el plus que contienen sus propuestas y que tienden todas ellas a superar el legalismo de los fariseos. La fórmula repetida con la que se expresa, más que nuevos mandatos, una nueva actitud es la siguiente: "Les han enseñado a ustedes... pero yo les digo" (Mt 5, 21.27.31.33.38.43). Todas ellas conducen al centro alrededor del que gravita toda la proclama y en el que radica toda la novedad del mensaje de Jesús, por lo que fue percibido como buena noticia: "sean buenos del todo, como es bueno totalmente el Padre de ustedes que está en los cielos" (Mt 5, 48) ${ }^{41}$.

La bondad del Padre consiste en el amor gratuito que no hace distinción entre justos y pecadores al repartir sus beneficios $(5,45)$ y se decanta por los afligidos y oprimidos (5, 1-10). En el resto del Sermón de la Montaña la "mayor fidelidad" exigida tiene como punto de referencia obligado, no la Ley, sino la presencia y la actividad del Padre (Mt 6, 1.4.6.8.9.15.18.26.32; 7, 11.21).

40. Cfr. L. A. Schökel y J. Mateos, Primera lectura de la Biblia, Madrid, 1975, p. 315.

41. Para la justificación de esta traducción de téleios en el contexto véase J. Mateos y

F. Camacho, El evangelio de Mateo. Lectura comentada, Madrid, 1981, ad loc. 